\title{
INDIAN POLICY OF JOHN ADAMS ADMINISTRATION: TREATIES WITH THE INDIANS
}

\author{
Timur V. Nelin \\ Volgograd State University, Volgograd, Russian Federation
}

\begin{abstract}
In this article the author examines the treaties that were concluded with the Native Americans in the period of John Adams presidency. Treaties with the Natives can be a good source for the study of the US Indian policy. They help to understand the character of Indian-white relations, the attitudes of Federal authorities towards certain Indian nation, the actual problems of the Frontier and so on. Unfortunately the policy of the second President of the USA toward the Native Americans is investigated not so good as the policy of other Presidents of Early American Republic. The study of the treaties helps to know more about John Adams Indian policy. In the years of his presidency only few agreements were signed with the Native American tribes. These were the Mohawk, the Seneca, the Oneida of the Iroquois Nation and the Cherokee. The procedure of Indian-white agreements was well developed until 1797 year. And John Adams administration did not explore something new in this question. The second President of the United States adopted the George Washington's principals of dealing with the Natives. But in fact he had to consider the internal and external situation in the country. The treaties with the Indians, concluded by the administration of John Adams did not become a bright episode of American history. However they helped to reduce tensions in US-Indian relations.
\end{abstract}

Key words: U.S. history, John Adams, Native Americans, Indian policy, treaties with Indian tribes, Iroquois, Cherokee.

УДК 94(73)“1797/1801”

Дата поступления статьи: 23.02.2016

ББК 63.3(7)51

Дата принятия статьи: 12.03.2016

\section{ИНДЕЙСКАЯ ПОЛИТИКА АДМИНИСТРАЦИИ ДЖОНА АДАМСА: ДОГОВОРЫ С ИНДЕЙЦАМИ}

\author{
Тимур Владимирович Нелин \\ Волгоградский государственный университет, г. Волгоград, Российская Федерация
}

\begin{abstract}
Аннотация. В статье рассматриваются договоры, которые были заключены с индейцами в годы президентства Джона Адамса. Договоры с коренными американцами являются хорошим источником для исследования индейской политики США. Поскольку политика второго президента страны в отношении коренных американцев изучена недостаточно, исследование названных документов восполняет этот пробел. При Дж. Адамсе были подписаны соглашения с племенами ирокезов и чероки. В самой процедуре заключения договоров Дж. Адамс во многом опирался на тот механизм ведения дел с индейцами, который был разработан при Дж. Вашингтоне. Кроме того, Дж. Адамсу приходилось учитывать общую обстановку не только в индейском вопросе, но и в стране. Хотя договоры с индейцами, заключенные администрацией Дж. Адамса, не стали ярким историческим событием, они позволили снизить напряженность в американо-индейских отношениях.

Ключевые слова: история США, Джон Адамс, коренные американцы, индейская политика, договоры 웅 индейцами, ирокезы, чероки.

Договоры с индейцами являются хорошим источником для исследования политики США в отношении аборигенов. По ним мож-

но судить о характере взаимоотношений властей с конкретным индейским племенем, приоритетах проводимой американскими властя-
\end{abstract}


ми политики, насущных проблемах фронтира, проблемах межкультурного диалога американцев с индейцами и т. д.

Сама по себе договорная система - это один из элементов индейской политики США. После ратификации договоры были обязательны для исполнения. Основные вопросы, которые в них затрагивались, - это положения о мире, союзничестве, земельные уступки, обозначение границ проживания белых и индейцев, правила поведения на границе, иногда вопросы торговли, размещения агентств и т. д.

Учитывая то обстоятельство, что индейская политика администрации Дж. Адамса изучена недостаточно, о чем, в частности, обстоятельно пишет в своей статье американский историк Дэниел Уснер, следует обратить особое внимание на договоры, которые были заключены во время нахождения у власти второго президента США [36, p. 608].

Для лучшего понимания проводимой Дж. Адамсом политики нужно сказать несколько слов о той системе договоров с коренными американцами, которая сформировалась в США к 1797 году.

Со времен Войны за независимость 1775-1783 гг. и до 1797 г. американские власти заключили договоры с племенами ирокезов, делаварами, шауни, народами Северо-западной территории и с четырьмя цивилизованными племенами юга США: чероки, чокто, чикасо и криками. Практически во всех этих соглашениях ключевым пунктом был земельный вопрос. Иногда он сводился просто к обозначению границы проживания племени, иногда, как это было, например, в Гринвилльском договоре 1795 г. с индейцами Северо-Запада, к вопросу значительных уступок племенных территорий белым колонистам [35]. Вообще Гринвилльский договор был достаточно болезненным для индейцев и стал немалым бременем для администрации Дж. Адамса, во многом определив и стратегию второго президента в решении индейского вопроса - максимально избегать конфликтных ситуаций.

Особенность всех заключенных договоров с индейцами была в том, что они по форме напоминали международные договоры и проходили ту же процедуру ратификации. На самом деле, как отмечает один из наиболее авторитетных исследователей индейской полити- ки США Фрэнсис Пол Пруча, договоры с индейцами, несмотря на форму, никогда международными не являлись [24, p. 21]. Соответственно все вопросы относительно отчуждения индейских земель следует рассматривать как вопросы внутригосударственные.

К 1797 г. в США был сформирован и налажен механизм заключения соглашений с коренными американцами. За организацию договоров с племенами фронтира отвечал военный департамент. За организацию договоров с племенами, проживавшими внутри штатов, - отдельные штаты. Базовым законом, определявшим специфику договоров, был закон 1796 г. о торговле и взаимоотношениях с индейцами. В нем оговаривались не только основные правила поведения на границе, которые собственно должны были отражаться в договорах, но и сами условия заключения договоров с индейцами, и роль президента в этом вопросе. В статье 20, например, говорилось, что президент США имеет исключительное право устанавливать границы США с любым индейским племенем посредством заключения договора с этим племенем [7, p. 474].

Естественно, что на процедуре заключения договора сам президент не присутствовал. Его представлял специальный уполномоченный комиссар. Должность комиссара была введена еще Континентальным Конгрессом в 1775 году. Каждый комиссар отвечал за вверенный ему департамент и вел дела с теми племенами, которые в этом департаменте проживали. Такая схема работы с индейцами хорошо себя зарекомендовала с колониальных времен [1, с. 62]. В 1786 г. Планом управления делами индейцев по аналогии с должностью комиссара вводилась должность суперинтенданта [9, p. 2141]. При Дж. Вашингтоне для заключения договора с аборигенами опять назначались комиссары, но только эта должность была не постоянной, а временной, в каждом конкретном случае и специальным указом президента. Комиссаром мог быть военный министр, губернатор территории, военный офицер (как в случае с Гринвилльским договором 1795 г.), конгрессмен и т. д.

Одно из последних распоряжений Дж. Вашингтона, которое касалось индейцев, было отдано 2 марта 1797 года. По сути это было разъяснение Сенату о необходимости 
заключения договора с племенем сенека относительно покупки у индейцев земельного участка. Комиссаром в этом вопросе президент назначил конгрессмена от Нью-Джерси Айзека Смита [11].

Совершенно очевидно, что организацией выполнения договора с сенека пришлось заниматься уже администрации Дж. Адамса. Сделка не должна была стать и, собственно говоря, не стала чем-то особенно выдающимся для Соединенных Штатов, она просто касалась продажи индейцами части своих земель в штате Нью-Йорк американскому финансисту Роберту Моррису за 100 тыс. долларов. Для самих сенека, напротив, эта сделка была достаточно значимой, поскольку оговаривала территорию дальнейшего проживания племени. Официальные власти США непосредственного участия в покупке земли не принимали, они лишь контролировали ход сделки. Соглашение с сенека, ставшее известным как Договор у Большого Дерева (Treaty of Big Tree), было заключено 15 сентября 1797 г. [2]. Со стороны индейцев его подписали 52 человека - вожди и выдающиеся воины племени, среди которых были такие известные предводители, как Прекрасное Озеро, Красный Мундир, Сеятель Кукурузы и др. Самого Р. Морриса на встрече не было, от его лица соглашение подписал его сын Томас Моррис. Не было и Айзека Смита, которого делегировал Дж. Вашингтон в качестве комиссара. В отчете перед Сенатом от 6 декабря 1797 г. Дж. Адамс пояснил, что А. Смит отказался от этой должности, а место комиссара занял член Исполнительного совета Коннектикута, полковник Джереми Уодсворт [17].

Что же касается А. Смита, то он курировал заключение договора с другим племенем ирокезов - с могавками. Это произошло чуть раньше, 29 марта 1797 г. [31]. Согласно этому договору, могавки Верхней Канады отказывались от своих притязаний на земли штата Нью-Йорк. Белые были представлены комиссаром США А. Смитом и тремя агентами штата Нью-Йорк: Авраамом Тен Бруком, Эгбертом Бенсоном и Эзрой Л'Омдье. Со стороны индейцев договор подписали широко известный вождь могавков Джозеф Брант и менее известный Джон Дезеронто. Несмотря на то, что договор с могавками был зак- лючен раньше, чем с сенека, Дж. Адамс передал его на рассмотрение Сената только 12 апреля 1798 года. При этом президент сообщил, что по какой-то случайности договориться с могавками долгое время не получалось и вот, наконец, это произошло [16].

Здесь необходимо внести некоторые разъяснения относительно той случайности, о которой говорил Дж. Адамс. Дело в том, что со времен Войны за независимость 17751783 гг. Лига ирокезов пережила раскол: онейда и тускарора поддержали колонистов, а могавки, сенека, кайюга и онондага - Великобританию. После обретения независимости Соединенные Штаты заключили в 1784 г. мирный договор с ирокезами, который стал известен как Договор Форта Стенвикс [34]. Помимо мирного соглашения, этот договор подразумевал уступку части земель четырех племен ирокезов американцам. Эти четыре племени были теми, кто поддерживал Великобританию. Союзникам США - онейда и тускарора - давались гарантии сохранения их племенных земель. Могавки были представлены не полностью, часть племени под предводительством Джозефа Бранта в подписании договора не участвовала, а соответственно не соглашалась с его положениями. В 1789 г. в Форте Хармар положения договора были обновлены по той же схеме, что и в Договоре Форта Стенвикс, с теми же земельными уступками, при этом отдельно оговаривалось, что могавков это новое соглашение не касается [32, p. 24]. Такая ситуация была связана с тем, что представители племени не присутствовали на встрече. В 1794 г. был заключен еще один договор с ирокезами, опять по поводу племенных границ проживания и опять без участия могавков [33].

Как можно видеть, к моменту вступления Дж. Адамса в должность президента страны соглашение с могавками так и не было заключено, о чем собственно президент и сообщал Сенату. Кроме того, все эти договоры показали, что иметь дело с ирокезами как единой политической силой достаточно проблематично и к тому же невыгодно для самих американцев. Гораздо проще было договориться о земельных уступках с каждым племенем по отдельности. Поэтому после договора 1794 г. США больше не заключали 
соглашений с Лигой ирокезов, а имели дело с отдельными племенами.

Примечательно, что в своем первом ежегодном послании Конгрессу от 22 ноября 1797 г. Дж. Адамс вообще не упомянул о двух заключенных договорах с индейцами. Это может говорить как о том, что их важность в национальном масштабе была незначительной, так и о том, что Дж. Адамс не считал их заслугой своей команды.

Следующий договор, который администрации Дж. Адамса необходимо было заключить с в индейцами, относился к племени чероки. Основным документом, определявшим американо-черокские отношения на тот период, был Холстонский договор 1791 г. [28]. В 1794 г. в Филадельфии было заключено еще одно соглашение с чероки, но, согласно его пятой статье, оно было лишь как дополнение к Холстоновскому договору [29, p. 34]. В любом случае, с дополнением или без, Холстонский договор был неоднозначным в вопросе границы между белыми и индейцами. Об этом казусе специальная комиссия по земельным притязаниям Теннеси во главе с конгрессменом от Южной Каролины Томасом Пинкни сообщила Палате представителей 20 декабря 1797 года ${ }^{1}$. Комиссия обращала внимание на то обстоятельство, что белые поселенцы пренебрегают положениями договора и селятся на землях, которые чероки считают своими, и что такие действия идут вразрез с законом о торговле и взаимоотношениях с индейцами 1796 г. [27].

Палата представителей 28 декабря направила военному министру резолюцию с просьбой прояснить ситуацию о границе с чероки, ответ был получен 5 января 1798 года. Военный министр Джеймс Мак-Генри, основываясь на материалах переписки своего ведомства, предоставил информацию, подтверждавшую наличие проблемы. Речь в отчете военного министра, однако, не шла о том, что белые селятся нелегально на землях чероки. Было сказано, что граница четко не определена и, как следствие, возникают вольные трактовки, где можно селиться, а где нет, что создает напряженность между двумя народами [15].

Уже 8 января 1798 г. Дж. Адамс сообщил Сенату, что необходимо заключить новый договор с чероки и что для этой цели он на- значил трех комиссаров: соратника по партии, бывшего конгрессмена от Массачусетса Фишера Эймса; юриста из Вирджинии Бушрода Вашингтона, племянника Дж. Вашингтона, и юриста из Северной Каролины, ярого федералиста Альфреда Мура [20].

Совершенно очевидно, что для организации договора с чероки необходимо было дополнительное финансирование. В этой связи 27 февраля 1798 г. был принят соответствующий акт о выделении суммы в 25880 долларов на заключение договоров с индейцами [3]. Хотя в самом документе не указывалось, что деньги выделены, прежде всего, для организации договора с чероки, вполне очевидно, что это было так.

Из предложенных президентом страны комиссаров к концу марта 1798 г. остался только А. Мур. Вместо Ф. Эймса и Б. Вашингтона, которые отказались от предложенной должности, назначались бывший сенатор от Джорджии Джордж Уолтон и контролер Казначейства (Comptroller of the Treasury) Джон Стил из Вирджинии [21].

30 марта 1798 г. военный министр направил новым комиссарам инструкции относительно договора с чероки. Согласно этим инструкциям, комиссары должны были уговорить чероки продать ту часть своих земель, которая была наиболее выгодна для штата Теннеси, естественно, с целью защиты проживавших на этих землях граждан штата. Предлагалось четыре варианта границы и соответственно четыре варианта компенсации за проданные земли. Начинать переговоры нужно было с наиболее выгодного и в случае несогласия индейцев постепенно переходить к менее значимым. После согласования земельного вопроса комиссары должны были оговорить другие вопросы, связанные с границей. В частности, следовало убедить чероки, что нарушившие границу белые будут депортированы; что индейцы не должны препятствовать американским властям нанимать милицию на пограничной территории, дабы отлавливать тех людей, которые настраивают аборигенов против американцев, а также тех, кто не от лица США ведет переговоры о покупке у чероки какого-либо куска земли и т. д. [13]. По сути все эти дополнительные права американцев должны были обеспечивать мир с индейцами, что собствен- 
но вписывалось в идею Дж. Адамса, высказанную в его первом ежегодном обращении к Конгрессу относительно борьбы с иностранными агентами, подстрекавшими индейцев к конфликту [10, p. 251-252].

27 августа 1798 г. военный министр направил комиссарам дополнительные инструкции. К тому моменту комиссаров было двое: Дж. Уолтон и вновь назначенный подполковник Томас Батлер. Сообщалось, что А. Мур вернулся домой, а Дж. Стил отказался от должности. В этих инструкциях пояснялось, что первые три варианта границы, хоть и желательны, но маловероятны в достижении. Четвертый же вариант, таким образом, - самый реалистичный. При этом отмечалось, что комиссары не должны держаться строгой формулировки четвертого варианта и, если индейцы откажутся продавать обозначенные земли, надо стараться выторговать по максимуму [14].

Тогда же, 27 августа 1798 г., было составлено и обращение Дж. Адамса к индейцам чероки, в котором он разъяснял сложившуюся ситуацию и представлял комиссаров. Ключевая идея всего обращения заключалась в том, что договор направлен на поддержание мира с индейцами и преимущественно для обеспечения их интересов. В этой связи президент упомянул об учрежденной у блокпоста Теллико фактории, где чероки могли приобрести необходимые им товары по низким ценам и все, что нужно для занятия земледелием и ремеслами белых людей. Там же индейцы могли получить и инструкции, как пользоваться инструментами белого человека [26].

Упомянутый в обращении к индейцам торговый пост был основан, однако, не при Дж. Адамсе, а еще при Дж. Вашингтоне в 1795 г. [25, p. 584].

Договор с чероки был заключен 2 октября 1798 г. недалеко от блокпоста Теллико, в связи с чем он также стал известен как Первый договор у Теллико. Со стороны Соединенных Штатов договор подписали Дж. Уолтон и Т. Батлер, со стороны индейцев - 39 вождей и воинов племени, в качестве свидетелей выступили еще 14 человек, включая индейского агента среди чероки Сайласа Динсмура и переводчика-полукровку Чарльза Р. Хикса. По своей сути этот договор стал добавлением к Холстоновскому договору 1791 г., что видно из преамбулы [30, p. 51-52]. Договор состоял из 10 статей. Основным вопросом естественно стал земельный вопрос. Чероки уступили Соединенным Штатам земли на территории нынешнего восточного Теннеси. Описание границы в статье 4 договора отличалось от тех вариантов, которые предлагались в инструкции к комиссарам от 30 марта 1798 года. Однако, судя по оговоренной в статье 6 компенсации, уступленные территории были ближе к четвертому варианту, на который и обращалось внимание комиссаров в инструкциях от 27 августа 1798 года.

Помимо земельного вопроса, договор подтверждал мирные отношения белых и чероки, за индейцами оставалось право охотиться на проданных землях, оговаривался вопрос компенсаций за украденных у белых или у индейцев лошадей и т. Д. На рассмотрение Сената этот договор Дж. Адамс передал 15 января 1799 г. [18].

Хотя Договор у Теллико стал ключевым событием индейского вопроса в 1798 г., нельзя не упомянуть еще об одном соглашении с индейцами, которое было заключено в том же году. Это был договор с ирокезским племенем онейда.

3 мая 1798 г. Дж. Адамс сообщил Сенату, что, по словам губернатора Нью-Йорка Джона Джея, племя онейда предложило уступить штату часть своих земель. Для заключения соответствующего договора президент назначил комиссара Джозефа Хопкинсона, 27-летнего юриста из Пенсильвании [22].

Соглашение с онейда было подписано 1 июня 1798 года ${ }^{2}$. Кроме комиссара Дж. Хопкинсона белых представляли агенты штата Нью-Йорк: Эгберт Бенсон, Эзра Л’Омдье и Джон Тэйлор. Текст договора Дж. Адамс представил на рассмотрение Сената 31 января 1799 г. [19]. По своей сути это соглашение напоминало то, что было заключено с сенека в 1797 г.: индейцы уступали часть своей территории штату Нью-Йорк, а назначенный президентом комиссар просто контролировал ход сделки.

Как и за год до этого, заключение договоров с индейцами никак не было отмечено в ежегодном послании Дж. Адамса Конгрессу.

В феврале 1799 г. было принято сразу два акта относительно финансового обеспечения 
сделок с индейцами. Согласно первому от 19 февраля, Конгресс выделял президенту сумму в 25 тысяч долларов на возможные договоры с индейцами и связанные с этим расходы [4]. Второй акт от 25 февраля предусматривал выделение средств для ежегодной выплаты индейцам, согласно тем положениям о компенсациях, которые были оговорены в самих договорах с этими индейцами. В частности, упоминались два договора с криками от 7 апреля 1790 г. и от 29 июня 1796 г.; договор с шестью племенами ирокезов от 11 ноября 1794 г.; соглашение с чикасо от 15 июля 1794 г.; договор с чероки от 2 октября 1798 г. и также Холстонский договор 1791 года. Согласно данному акту, деньги из налогов, которые еще не были потрачены на какие-либо иные нужды, должны были быть пущены на выплату ежегодных рент по условиям выше обозначенных договоров [5, p. 619].

Как можно видеть, большинство договоров, упомянутых в акте от 25 февраля 1799 г., было заключено еще при Дж. Вашингтоне. Таким образом, выделяя средства, Конгресс фактически позволял Дж. Адамсу продолжать реализацию соглашений предыдущей администрации. Этот момент, с одной стороны, кажется вполне логичным и естественным - выполнять перед индейцами обязательства, которые взяли на себя США; с другой стороны, он свидетельствует о том, что по большому счету администрация Дж. Адамса и Конгресс были согласны с индейской политикой, которую проводил первый президент страны.

В марте 1799 г. был принят новый закон о торговле и взаимоотношениях с индейцами [8]. Однако ничего принципиально нового по сравнению с аналогичным законом 1796 г. он не вводил. Принятие было обусловлено окончанием срока действия предыдущего закона. При этом просто отказаться от утратившего силу закона 1796 г. было нельзя. Именно в его рамках действовала администрация Дж. Адамса при организации договоров с индейцами, на этот закон ссылался в своем докладе Т. Пинкни, к нему же апеллировал Дж. Хопкинсон [23; 27].

13 мая 1800 г. конгрессмены вновь выделили деньги президенту страны в размере 15 тысяч долларов в этот раз для заключения договора с индейцами к югу от р. Огайо [6]. Тем не менее со стороны президентской ад- министрации никакой деятельности по заключению предполагаемого договора не последовало. В 1800 г. вообее никаких новых договоров с коренными американцами не было заключено. Объяснить эту ситуацию тем обстоятельством, что такой необходимости не было, нельзя. Выделение денег президенту для организации договора с индейцами само по себе говорит о том, что такая проблема назрела. Но здесь сыграли роль другие факторы, помешавшие Дж. Адамсу продолжать политику договоров с аборигенами. Эти факторы не были связаны с индейским вопросом, а проистекали из сложной политической обстановки в стране.

Таким образом, как можно видеть, все договоры, которые были заключены администрацией Дж. Адамса с индейцами, пришлись на первую половину его президентского срока. Это были соглашения с ирокезоязычными народами: могавками, сенека, чероки и онейда. Из них только договор с чероки был заключен от лица федеральных властей, три другие - от лица штата Нью-Йорк. Ключевым пунктом всех договоров был земельный вопрос, и все они по сути стали продолжением деятельности предыдущей администрации. Тем не менее характер этих договоров показывает аккуратность администрации Дж. Адамса в отношении индейцев, что хорошо вписывается в главную линию его индейской политики - сохранять мир с коренными американцами.

\section{ПРИМЕЧАНИЯ}

${ }^{1}$ В записях дебатов Конгресса не всегда фигурирует имя докладчика. В данном случае просто указан «Мистер Пинкни». Однако именно Томас Пинкни был в тот период членом Палаты представителей Конгресса США, в рамках которой и был создан комитет.

2 Этого договора нет в сборнике договоров Чарльза Капплера [12]. Однако текст есть в самом послании Дж. Адамса к Сенату [19].

\section{СПИСОК ЛИТЕРАТУРЫ}

1. Нелин, Т. В. Торговые отношения США с индейцами в годы Войны за независимость (17751783 ) / Т. В. Нелин // Вестник Волгоградского государственного университета. Серия 4, История. Регионоведение. Международные отношения. - 
2012. - № 2 (22). - C. 61-68. - DOI: http://dx.doi.org/ 10.15688/jvolsu4.2012.2.9.

2. Agreement with the Seneca. Sept. 15. 1797 // Indian Affairs: Laws and Treaties. In 7 vols / comp. and ed. by C. J. Kappler. - Washington, D. C. : Government Printing Office, 1904. - Vol. 2 : Treaties. P. $1027-1030$.

3. An Act appropriating a certain sum of money to defray the expense of holding a Treaty or Treaties with the Indians. Feb. 27. 1798 // United States Statutes at Large, 1789-1875. In 18 vols / ed. by R. Peters. Boston : Charles C. Little and James Brown, 1845.Vol. 1. - P. 539-540.

4. An Act appropriating a certain sum of money to defray the expense of holding a Treaty or Treaties with the Indians. Feb. 19. 1799 // United States Statutes at Large. - Boston, 1845. - Vol. 1. - P. 618.

5. An Act making appropriations for defraying the expenses which may arise, in carrying into effect certain Treaties between the United States and several tribes or nations of Indians. Feb. 25. 1799 // United States Statutes at Large. - Boston, 1845. - Vol. 1. - P. 618-619.

6. An Act to appropriate a certain sum of money to defray the expense of holding a treaty or treaties with the Indians. May 13. 1800// United States Statutes at Large. - Boston, 1845. - Vol. 2. - P. 82.

7. An act to regulate trade and intercourse with the Indian tribes, and to preserve peace on the frontiers. May 19. 1796 // United States Statutes at Large. - Boston, 1845. - Vol. 1. - P. 469-474.

8. An act to regulate trade and intercourse with the Indian tribes, and to preserve peace on the frontiers. March 3. 1799 // United States Statutes at Large. - Boston, 1845. - Vol. 1. - P. 743-749.

9. An Ordinance for the Regulation of Indian Affairs. Aug. 7. 1786// The American Indian and the United States. A Documentary history / ed. by W. E. Washburn. - N. Y. : Random House, 1973. Vol. 3. - P. 2140-2143.

10. First Annual Address of John Adams. Nov. 22. 1797 // A Compilation of the Messages and Papers of the Presidents, 1789-1897. In 11 vols / ed. by J. D. Richardson. - Washington, D. C. : Government Printing Office, 1896. - Vol. 1. 1789-1817. -P. 250-254.

11. George Washington to the Senate. March 2. 1797 // American State Papers. Documents, legislative and executive, of the Congress of the United States: Class 2: Indian Affairs. In 2 vols / ed. by W. Lowrie and M. St. Clair Clarke. - Washington, D. C. : Gales and Seaton, 1832. - Vol. 1. - P. 626.

12. Indian Affairs: Laws and Treaties. Washington, D. C., 1904. - Vol. 2. - 1099 p.

13. James McHenry to Alfred Moore, George Walton, and John Steel. March 30. 1798 // American State Papers. Indian Affairs. - Washington, D. C., 1832. - Vol. 1. - P. 639-640.
14. James McHenry to George Walton, Esquire, and Lieutenant Colonel Thomas Butler. Aug. 27. 1798 // American State Papers. Indian Affairs. - Washington, D. C., 1832. - Vol. 1. - P. 640.

15. James McHenry to the House of Representatives. Jan. 5. 1798 // American State Papers. Indian Affairs. Washington, D. C., 1832. - Vol. 1. - P. 628-631.

16. John Adams to the Senate. Apr. 12. 1798 // American State Papers. Indian Affairs. - Washington, D. C., 1832. - Vol. 1. - P. 636.

17. John Adams to the Senate. Dec. 6. 1797 // American State Papers. Indian Affairs. - Washington, D. C., 1832. - Vol. 1. - P. 626.

18. John Adams to the Senate. Jan. 15. 1799 // American State Papers. Indian Affairs. - Washington, D. C., 1832. - Vol. 1. - P. 637.

19. John Adams to the Senate. Jan. 31. 1799 // American State Papers. Indian Affairs. - Washington, D. C., 1832. - Vol. 1. - P. 641.

20. John Adams to the Senate. Jan. 8. 1798 // American State Papers. Indian Affairs. - Washington, D. C., 1832. - Vol. 1. - P. 631.

21. John Adams to the Senate. March 23. 1798 // Journal of the Executive Proceedings of the Senate of the United States of America, 1789-1875. In 21 vols / United States. Congress. Senate. - Washington,

D. C. : DuffGreen, 1828. - Vol. 1. - P. 266-267.

22. John Adams to the Senate. May 3. 1798 // American State Papers. Indian Affairs. - Washington, D. C., 1832. - Vol. 1. - P. 636.

23. Joseph Hopkinson to Timothy Pickering. June 31. 1798// American State Papers. Indian Affairs. Washington, D. C., 1832. - Vol. 1. - P. 643.

24. Prucha, F. P. The Great Father. The United States Government and the American Indians / F. P. Prucha. - Lincoln (Neb.) ; L. : University of Nebraska Press, 1986. $-426 \mathrm{p}$.

25. Report of the Secretary of War of the measures taken for opening a trade with the Indians. Dec. 12. 1795 // American State Papers. Indian Affairs. Washington, D. C., 1832. - Vol. 1. - P. 583-584.

26. Talk of the President of the United States to his beloved chiefs, warriors, and children, of the Cherokee nation. Aug. 27. 1798 // American State Papers. Indian Affairs. - Washington, D. C., 1832. Vol. 1. - P. 640-641.

27. Thomas Pinckney to the House of Representatives. Dec. 20. 1797 // American State Papers. Indian Affairs. - Washington, D. C., 1832. Vol. 1. - P. 628.

28. Treaty with the Cherokee. July 2. $1791 / /$ Indian Affairs: Laws and Treaties. - Washington, D. C., 1904. - Vol. 2. - P. 29-33.

29. Treaty with the Cherokee. June 26. 1794 // Indian Affairs: Laws and Treaties. - Washington, D. C., 1904. - Vol. 2. - P. 33-34. 
30. Treaty with the Cherokee. Oct. 2. $1798 / /$ Indian Affairs: Laws and Treaties. - Washington, D. C., 1904. - Vol. 2. - P. 51-55.

31. Treaty with the Mohawk Indians. March 29. 1797 // Indian Affairs: Laws and Treaties. Washington, D. C., 1904. - Vol. 2. - P. 50-51.

32. Treaty with the Six Nations. Jan. 9. 1789 // Indian Affairs: Laws and Treaties. - Washington, D. C., 1904. - Vol. 2. - P. 23-25.

33. Treaty with the Six Nations. Nov. 11. 1794 // Indian Affairs: Laws and Treaties. - Washington, D. C., 1904. - Vol. 2. - P. 34-37.

34. Treaty with the Six Nations. Oct. 22. 1784 // Indian Affairs: Laws and Treaties. - Washington, D. C., 1904. - Vol. 2. - P. 5-6.

35. Treaty with the Wyandot, etc. Aug. 3. 1795 // Indian Affairs: Laws and Treaties. - Washington, D. C., 1904. - Vol. 2. - P. 39-45.

36. Usner, D. H. "A Savage Feast They Made Of It": John Adams and the Paradoxical Origins of Federal Indian Policy / D. H. Usner // Journal of the Early Republic. - 2013. -Vol. 33, № 4 (Winter). - P. 607-641.

\section{REFERENCES}

1. Nelin T.V. Torgovye otnosheniya SShA s indeytsami v gody Voyny za nezavisimost (1775-1783) [Trade Relations Between the USA and Native Americans During the War for Independence (17751783)]. Vestnik Volgogradskogo gosudarstvennogo universiteta. Seriya 4, Istoriya. Regionovedenie. Mezhdunarodnye otnosheniya [Science Journal of Volgograd State University. History. Area Studies. International Relations], 2012, no. 2 (22), pp. 61-68. DOI: http://dx.doi.org/10.15688/jvolsu4.2012.2.9.

2. Agreement with the Seneca. Sept. 15. 1797. Kappler C. J., comp. and ed. Indian Affairs: Laws and Treaties, Washington, D. C., Government Printing Office, 1904, vol. 2: Treaties, pp. 1027-1030.

3. An Act appropriating a certain sum of money to defray the expense of holding a Treaty or Treaties with the Indians. Feb. 27. 1798. Peters R., ed. United States Statutes at Large, 1789-1875. Boston, Charles C. Little and James Brown, 1845, vol. 1, pp. 539-540.

4. An Act appropriating a certain sum of money to defray the expense of holding a Treaty or Treaties with the Indians. Feb. 19. 1799. Peters R., ed. United States Statutes at Large. Boston, 1845, vol. 1, p. 618 .

5. An Act making appropriations for defraying the expenses which may arise, in carrying into effect certain Treaties between the United States and several tribes or nations of Indians. Feb. 25. 1799. Peters R., ed. United States Statutes at Large. Boston, 1845, vol. 1, pp. 618-619.
6. An Act to appropriate a certain sum of money to defray the expense of holding a treaty or treaties with the Indians. May 13. 1800. Peters R., ed. United States Statutes at Large. Boston, 1845, vol. 2, p. 82.

7. An act to regulate trade and intercourse with the Indian tribes, and to preserve peace on the frontiers. May 19. 1796. Peters R., ed. United States Statutes at Large. Boston, 1845, vol. 1, pp. 469-474.

8. An act to regulate trade and intercourse with the Indian tribes, and to preserve peace on the frontiers. March 3. 1799. Peters R., ed. United States Statutes at Large. Boston, 1845, vol. 1, pp. 743-749.

9. An Ordinance for the Regulation of Indian Affairs. Aug. 7. 1786. Washburn W. E., ed. The American Indian and the United States. A Documentary history. N. Y., Random House, 1973, vol. 3, pp. 2140-2143.

10. First Annual Address of John Adams. Nov. 22. 1797. Richardson J. D., ed. A Compilation of the Messages and Papers of the Presidents, 1789-1897. Washington, D. C., Government Printing Office, 1896, vol. 1. 1789-1817, pp. 250-254.

11. George Washington to the Senate. March 2. 1797. Lowrie W., St. Clair Clarke M., eds. American State Papers. Documents, legislative and executive, of the Congress of the United States: Class 2 : Indian Affairs. Washington, D. C., Gales and Seaton, 1832, vol. 1, p. 626.

12. Kappler C. J., comp. and ed. Indian Affairs: Laws and Treaties, Washington, D. C., 1904, vol. 2, 1099 p.

13. James McHenry to Alfred Moore, George Walton, and John Steel. March 30. 1798. Lowrie W., St. Clair Clarke M., eds. American State Papers. Indian Affairs. Washington, D. C., 1832, vol. 1, pp. 639-640.

14. James McHenry to George Walton, Esquire, and Lieutenant Colonel Thomas Butler. Aug. 27. 1798. Lowrie W., St. Clair Clarke M., eds. American State Papers. Indian Affairs. Washington, D. C., 1832, vol. 1, p. 640.

15. James McHenry to the House of Representatives. Jan. 5. 1798. Lowrie W., St. Clair Clarke M., eds. American State Papers. Indian Affairs. Washington, D. C., 1832, vol. 1, pp. 628-631.

16. John Adams to the Senate. Apr. 12. 1798. Lowrie W., St. Clair Clarke M., eds. American State Papers. Indian Affairs. Washington, D. C., 1832, vol. 1, p. 636.

17. John Adams to the Senate. Dec. 6. 1797. Lowrie W., St. Clair Clarke M., eds. American State Papers. Indian Affairs. Washington, D. C., 1832, vol. 1, p. 626.

18. John Adams to the Senate. Jan. 15. 1799. Lowrie W., St. Clair Clarke M., eds. American State Papers. Indian Affairs. Washington, D. C., 1832, vol. 1, p. 637.

19. John Adams to the Senate. Jan. 31. 1799. Lowrie W., St. Clair Clarke M., eds. American State 
Papers. Indian Affairs. Washington, D. C., 1832 , vol. 1, p. 641.

20. John Adams to the Senate. Jan. 8. 1798. Lowrie W., St. Clair Clarke M., eds. American State Papers. Indian Affairs. Washington, D. C., 1832, vol. 1, p. 631.

21. John Adams to the Senate. March 23. 1798. United States. Congress. Senate. Journal of the Executive Proceedings of the Senate of the United States of America, 1789-1875. Washington, D. C., DuffGreen, 1828. vol. 1. pp. 266-267.

22. John Adams to the Senate. May 3. 1798. Lowrie W., St. Clair Clarke M., eds. American State Papers. Indian Affairs. Washington, D. C., 1832, vol. 1, p. 636.

23. Joseph Hopkinson to Timothy Pickering. June 31. 1798. Lowrie W., St. Clair Clarke M., eds. American State Papers. Indian Affairs. Washington, D. C., 1832, vol. 1, p. 643.

24. Prucha F. P. The Great Father. The United States Government and the American Indians. Volumes I and II. Unabridged. Lincoln (Neb.), L., University of Nebraska Press, 1995, 1302 p.

25. Report of the Secretary of War of the measures taken for opening a trade with the Indians. Dec. 12. 1795. Lowrie W., St. Clair Clarke M., eds. American State Papers. Indian Affairs. Washington, D. C., 1832, vol. 1, pp. 583-584.

26. Talk of the President of the United States to his beloved chiefs, warriors, and children, of the Cherokee nation. Aug. 27. 1798. Lowrie W., St. Clair Clarke M., eds. American State Papers. Indian Affairs. Washington, D. C., 1832, vol. 1, pp. 640-641.
27. Thomas Pinckney to the House of Representatives. Dec. 20. 1797. Lowrie W., St. Clair Clarke M., eds. American State Papers. Indian Affairs. Washington, D. C., 1832, vol. 1, p. 628.

28. Treaty with the Cherokee. July 2. 1791. Kappler C. J., comp. and ed. Indian Affairs: Laws and Treaties, Washington, D. C., 1904, vol. 2, pp. 29-33.

29. Treaty with the Cherokee. June 26. 1794. Kappler C. J., comp. and ed. Indian Affairs: Laws and Treaties, Washington, D. C., 1904, vol. 2, pp. 33-34. 30. Treaty with the Cherokee. Oct. 2. 1798. Kappler C. J., comp. and ed. Indian Affairs: Laws and Treaties, Washington, D. C., 1904, vol. 2, pp. 51-55.

31. Treaty with the Mohawk Indians. March 29. 1797. Kappler C. J., comp. and ed. Indian Affairs: Laws and Treaties, Washington, D. C., 1904, vol. 2, pp. 50-51.

32. Treaty with the Six Nations. Jan. 9. 1789. Kappler C. J., comp. and ed. Indian Affairs: Laws and Treaties, Washington, D. C., 1904, vol. 2, pp. 23-25.

33. Treaty with the Six Nations. Nov. 11. 1794. Kappler C. J., comp. and ed. Indian Affairs: Laws and Treaties, Washington, D. C., 1904, vol. 2, pp. 34-37.

34. Treaty with the Six Nations. Oct. 22. 1784. Kappler C. J., comp. and ed. Indian Affairs: Laws and Treaties, Washington, D. C., 1904, vol. 2, pp. 5-6.

35. Treaty with the Wyandot, etc. Aug. 3. 1795. Kappler C. J., comp. and ed. Indian Affairs: Laws and Treaties, Washington, D. C., 1904, vol. 2, pp. 39-45.

36. Usner D. H. “A Savage Feast They Made Of It": John Adams and the Paradoxical Origins of Federal Indian Policy. Journal of the Early Republic, 2013, vol. 33, no. 4, pp. 607-641.

\section{Information About the Author}

Timur V. Nelin, Candidate of Sciences (History), Associate Professor, Department of International Relations, Political Science and Area Studies, Volgograd State University, Prosp. Universitetsky, 100, 400062 Volgograd, Russian Federation, nelin@volsu.ru.

\section{Информация об авторе}

Тимур Владимирович Нелин, кандидат исторических наук, доцент кафедры международных отношений, политологии и регионоведения, Волгоградский государственный университет, просп. Университетский, 100, 400062 г. Волгоград, Российская Федерация, nelin@volsu.ru. 